\title{
QUALITY INFORMATION IN PROJECT MANAGEMENT AND UGLIES OF PROJECT IN INDUSTRY
}

\author{
MALA, J[ana]; BIELIK - MARETTOVA, M[aria] \& CERNA, L[ubica]
}

\begin{abstract}
Poor quality of project management in modern organizations depends on many aspects. As such the size and nature of the project, human factors, organizational culture, experience and skills as a manager and other project team members, technology, but also the quality of inputs including, but not least, include quality information. Applying $P M B O K$ methodology use, istop awaw from 10 of uglies of project as is described in the paper and use PMIS, help organizations create effective management of its projects. The method of project control depends on all those aspects. The importance of the organization should be given to dispose of an optimum amount of information in the required quality and especially to share this information. Quality information is the key to the success of the project management, but also in many other areas. Understanding the mechanics of methodologies project management and clases is essential, but it is experience that distinguishes successful project managers.
\end{abstract}

Keywords: project management processes, $P M B O K$, projects quality information, uglies of projects

\section{INTRODUCTION}

The competitive pressures on organizations is still increased. This fact has led them to engage in projects that are critical to their performance. If organizations want to be successful they have to realize projects on time, within budget and project must meet the requirements for the management of project risks. Much time and many resources are dedicated to the selection and development of projects, but most important is that projects are properly implemented in organizations to achieve their objectives. For effective projects management organizations are using project management information systems, which are viewed as support for project management. Within project management is necessary to emphasize on quality of input information as well as their ongoing monitoring, coordination, editing throughout the project life cycle. Quality management is performed through the project life cycle with particular reference to quality planning, quality assurance, quality control and independent verification of quality.

\section{PROJECT MANAGEMENT PROCESSES}

The project is a group of processes, which are developing at the time of their existence and are situated at various stages. Process groups in the project management are the process activities in the project from initiation through planning, execution / coordination, monitoring and control to the completion of the project (according to Svozilová, Swalbe). To make the project successful, the project team has to: a. Select appropriate procedures within a group of project management processes (process groups),

b. Use a defined approach to adapt the product specifications and plans to meet requirements for product,

c. Meet the demands and needs of all involved sides,

d. Keep balance between competing opportunities in demand, time, cost, quality, resources and risks to produce quality products.

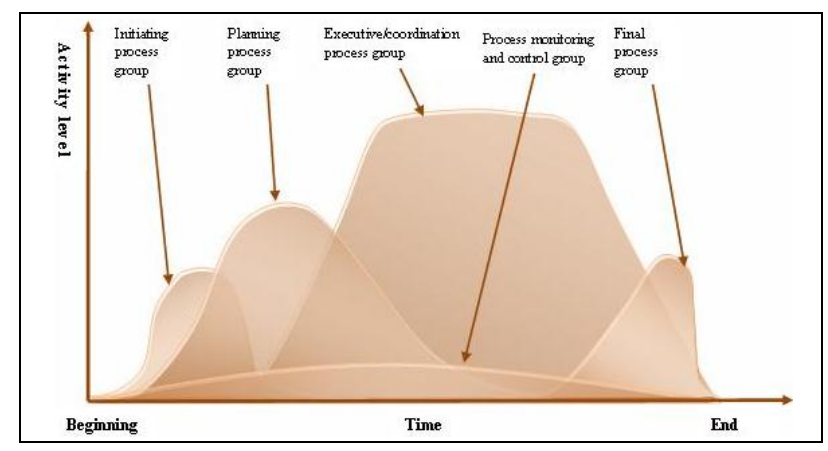

Fig. 1.The level of activity in each process group over time and their overlap (prepared according to [6])

Methodology PMBOK documents information necessary for initiating, planning, implementation, monitoring, management and completion of a project. Also identifies the processes of project management, which were recognized as "good practice" in most projects. These procedures are used globally, mostly in industry. "Good practice" means that compliance has been demonstrated that the use of these project management processes will increase the chances of success in larger scale of projects. This means that the knowledge, skills and processes mentioned above should always be applied uniformly to all projects. The project leader in collaboration with the project team is always responsible for determining the appropriate processes corresponding with degree of accuracy for each process of the project.

In respect of project management, we can define five project management process groups:

a. Initial procedural group - the main purpose is to create a basic definition of the project (project assignment - Project Charter) and obtain authorization for its implementation,

b. Procedural planning group - based on the project and it leads to more precise definitions of the scope of the project, the project is being analyzed in terms of time, 
cost, technology, methodologies and human resources,

c. Executive / procedural coordination group - activities focused on coordinating the planned work of the project,

d. Process monitoring and control group - activities focused on implementing the compliance performance of the project components with the project plan,

e. Procedural final group - the culmination of the project effort, resulting in customer acceptance of results [5].

In project management is required precision and accuracy of the information at the time, as incorrect information may result in better case to increased costs or extend the project timeframe, or to its early end and thus to waste of resources spent on individual project phases. The aim of all organizations is to ensure that such unwanted states will be avoided, respectively. to eliminate them as much as possible. To achieve the required condition to ensure the effectiveness of implemented projects, it is necessary for organization by collection, sharing and processing information, working on the set of uniform standards for the entire organization and have created a database-driven information. Methodology for mapping the 42 PMBOK project management processes into five project groups and the nine project management knowledge areas of project management. Each of the required process of project management is provided in a process group in which most activity takes place (e.g. if the process normally takes place during the planning and during project implementation is updated again, the process is placed in the group of planning a new process is not created). These activities are the main processes of knowledge areas.

PMBOK methodology is a tool to help organizations manage their projects, identify projects processes and different knowledge areas. PMBOK methodology does not guarantee success and quality of projects, but helps to achieve the desired goal. When managing projects according to the recommendations described in the PMBOK methodology is essential that organizations put a high emphasis on information that are used in all phases of projects. Collecting, sharing, archiving, and work with quality information leads to success and to ensure of their competitive advantage [3].

\section{TEN UGLIES OF PROJECTS}

Methodologies an classes of project management are adequate at explaining the mechanics of running project and tools used to do so. Understanding these mechanics is essential, but it is experience that distinguishes successful project managers.

Harold Kerzner in his book "Project management - Best Practices" describes 10 projects uglies and propose some resolutions. These 10 uglies are the ones that seem to be most common and have the biggest impact based on his experience. He describes them with a desctription of each ane some symptoms that indicate that these uglies may be happening.

1. Lack of maintained documentation

2. Pile phenomenon

3. No quality at source

4. Wrong people on the job

5. Not involve the right people

6. Not having proper sponsoring

7. No rigor around process

8. No community plan

9. Not plan for rework
10. Dates are just numbers

"Lack of maintained documentation - offentimes when projects are in a crunch, the first thing that gets eliminated is documentation. Sometimes documentation is not created even when projects do have the time. When documentation is created properly as projects continuous to progress, it is a ratity to see the documentation maintained.

\section{Symptoms:}

a. Requirement documents that do not match what was produced.

b. Technical documents that can't be used to maintain the technology because they are outdated.

c. No documentation on what decisions were made and why they were made.

d. No audit trail of changes made.

This is a problem since documentation provides the stewardship of the project. Kerzner means, that future projects and the people maintaining the project once it has been completed need to understand what was created, why it was created abd how it was created. Otherwise, they wind up falling into the same traps that happedn before [8]."

"Pile phenomenon - a question often asked towards the end of a project is "What is that under the rug?" the mainstream work always gets the primary focus on a project but it is those tangential things that get forgotten or pushed off until later, at which point there are several piles that need to be handled. Kurcer calls this the pile phenomenon, because team members think of it as a phenomenon that all this extra work has suddenly appeared at the end.

\section{Symptoms:}

a. Any work that gets identified as "we will do thi later" but is not on a plan somewhere.

b. Growing logs (defects, issues, ...)

c. Documentation assumed to be at the end.

There is no later accounted for in most project plans, and therefore these items either get dropped or there is a mad rush at the end to finish the work [8]."

"No quality at source - members of project teams don't always take on the mantra of quality at the source. There is sometimes a mentality that someone else will find the mistakes rather than a mentality of ownership of quality. Project managers don't always have the ability to review all work, so they must rely on their team members. Therefore the members of team must have the onus to ensure that whatever they put their name on represents their best work.

\section{Symptoms:}

a. Handing off work with errors before reviewing it.

b. Developing code without testing it.

c. Not caring about the presentation of work.

There are several studies that show that quality issues bot found at the source have an exponencial cost ehen found later in the project [8]."

"Wrong people on the job - project roles require the right match of skills and responsibilities. Sometimes a person's skill sed does not fr with role that she/he has been given.

Symptoms:

a. Team members being shown the same things repeatedly.

b. Consistent missing of dates.

c. Consistent poor quality.

As project managers, all we have are our resources. Not having the right fit for team members will result in working harder 
than necessary and impacts everyone else on the team who has to pick up the slack. There is also a motivational issue here? When team members are in the wrong roles, they may not feel challenged or feel that they are working to their potential. This has the impact of those persons not giving their best effort not embodying a solid work ethic when they normally would, feeling underutilized [8]."

"Not involve the right people - the people who know to make the project successful are the team members working on the project. Not involving the right team members at the right time can set the project up for failure before it begins.

\section{Symptoms:}

a. Having to make changes to work already completed.

b. Constant scope changes from the customers.

c. Lack of team buy-in to estimates.

d. Lack of ownership of decisions.

Not involving the right people up front in a project always results in changes to work. Not involving team members in decisions an estimates causes them to feel like they have no control over their work or the customers of the project [8]."

"Not having proper sponsorship - projects need internal and customer executive sponsorship to be successful. Sponsors act as tiebreakers and eliminate organizational politics/roadblocks that are holding up the project.

\section{Symptoms:}

a. Inadequate support from different areas of the organization and from customers stakeholders.

b. Issues taking very long before resolved.

c. Decision not being made efficiently.

Not having proper sponsorship can result in projects "spinning their wheeks". Also, when a change effort is involved, not having sponsorship can keep impactedemployees from buyinf in to a project [8]."

"Not rigor around process - almost every company uses a methodology for implementing projects. The success of these methodologies depends on the amount of rigor used on the project. Often, processes are not adhered to and projects run awry.

\section{Symptoms:}

a. Incomplete/nonexistent deliverables.

b. Inconsistencies within the project.

c. Lack of understanding of the project's big picture.

d. Lack of repeatable processes.

Processes are only as valuable as the rigidity on the,. In some companies, there are too many project management methodologies uses. Some are necessary due to the varying nature of eork, but basic project management practices and principles (using Project, Excel, ...) could easilybe standardized but are not. When one manager has to transition to another, this creates an extra layer of complexity, because a common language is not being used between the two people [8]."

"No community plan - project managers spend a significant amount of time on planning, extimating and scheduling activities. It these results are not shared with team members, then they don't know what they are working towards and can't manage their own schedules. This includes the communication of goals and items that are a big picture for team.

\section{Symptoms:}

a. Lack of knowledge about what is due and when it is due.

b. Missed dates.

c. Lack of ownership of deliverables.

d. Deliverables get forgotten.
Not having community plan will result is not having an informed community. Having a shared plan and goals helps to buld a cohesiveness and a grated understanding of how the work of each individual fits overall [8]."

"Dates are just numbers - schedule is a major driver of project success. Kurzer is amazed at the numner of people who think of dates as "suggestion" rather then deadlines. Because of interdependencies on projects, a missed date early on could ripple through the schedule for remainder of the project.

\section{Symptoms:}

a. Consistently missed dates.

b. Items left open for long periods of time.

c. Incomplete/nonexistent deliverables.

d. Lack of a sense of urgency on the project team.

Without structure around the management of dates, success requires a lot more effort. One other issue here is that of communication - these dates need to be communicated clearly and people must agree that this is their target. Also, they must understand what is on the critical path and what has slack, so if they slip on a critical path item, they know there is an impact on the procect or on another project within the same program [8]."

Focusing on proactive management, keeping up with work, and empowering the project teams are key to running a successful project.

\section{PROJECT MANAGEMENT SYSTEMS}

Systems for project management (Project Management Information System - PMIS) "provide to managers important information about the cost, project time, project performance parameters and links between these parameters" listed in Raymond and Bergeron by Cleand and King. The nature and role of the PMIS project management is characterized as support for the achievement of project objectives and implementation strategy of the project. PMIS support project managers in the tasks of planning, organizing, controlling, reporting and decision making at the same time. Scientific studies have shown that there are several important factors that support the use of PMIS:

a. Whether the project manager uses PMIS strongly depends on the quality of information generated in the PMIS,

b. Project managers more desire to use the information system if it provides an adequate level of details with respect to their needs,

c. It is important that the generated information will be simple, easily understood and can be easily shared among project team members,

d. PMIS must allow continuous monitoring of project progress [1].

Caniës and Bakens in their study were dealing with PMIS relationship between information quality and its impact on the quality of decision making. Project and excessive load with information is affecting the quality of the information in PMIS, while satisfaction with the use of PMIS with the quality of information affects decision-making process [2].

It follows that the organization can only handle so many projects simultaneously, how many available resources capacity it have. Procedures and processes can be useful for the project only if they are standardized and project staff knows what to do and how work should be done. Too much or too routine information may become a burden to project staff, too big administrative burden can shift attention from the real tasks of project management to process activities and too little routine creates a feeling of insecurity. 


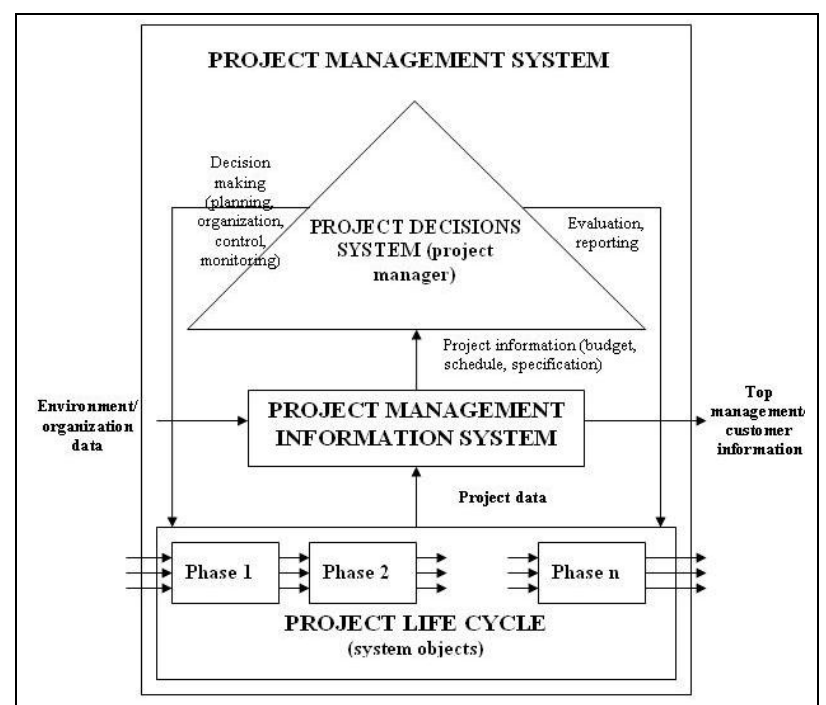

Fig. 2. Project management system (prepared according to [4])

\section{CONCLUSION}

Each project is unique and the way of his management depends on many aspects, for example. The size and nature of the project, human factors, organizational culture, experience and skills of manager and other project team members, technology, but also on quality of inputs including quality information. The main problem in many organization is not share the information, or share only some kind of information. And this ist the ground of misunderstanding and unsuccessful analysis and project auch.

The area of information quality in project management is not well specified and not clearly associated with the project of quality. For organizations, it is important to dispose with an optimum amount of information in the required quality and especially to share this information. Projects database maintenance can help organizations to prevent of any error status by any situation solving, respectively if such a situation occurs it may facilitate its solution based on previous experience from other projects that are recorded, not only in terms of time, but also in terms of cost and quality. The use of PMIS helps to the effective decision making and project management, helps to efficient redistribution of resources. For an organization it is important to think about how to capture, share, and not to lose and apply the right information at the right time and right place. Quality information is key to the success not only in project management, but also in many other areas.

In our further work we want to prepare further research in area of the information quality in project management in industrial companies in the Slovak Republic. Research will focus on the analysis of three selected topics:

a. The relationship between project management and use of IS and information quality,

b. The relationship between project management and information management in the are of information quality,

c. The relationship between selected indicators of project management quality and information quality.

d. The objective of my research will be to improve the quality of projects in industrial companies.

To my further research I set out a hypothesis related to the methodology of quality assessment information in project management. Hypotheses are constructed so that the most important information to assess the quality of project management:
Hypothesis 1: The relation between the rate of use in IS project management and quality information.

Hypothesis 2: Quality of information is a significant part of the applied methods and project management methodology applied in the Slovak industrial companies.

Hypothesis 3: The relation between the quality of information in project management and success of completed projects.

Previous researches of the project management in Slovak industrial enterprises managed at the Institute of industrial engineering, management and quality brought some interesting results in the area of project management maturity, training needs in project management, project management methods and methodologies applied in industrial enterprises (Holtan et al., 2009), multicultural project teams (Caganova et al., 2011 and ICT support of project management. Research of information quality in project management is a logical continuation of previeous researches with the objective to improve project quality in industrial enterprises [7].

\section{ACKNOWLEDGEMENTS}

This contribution is a component presenting the results of research VEGA 1/1203/12 Quality Management in project management in industrial enterprises, which is solved by Institute of Industrial Engineering, Management and Quality MTF STU.

\section{REFERENCES}

[1] Caniës, Marjolein, Bakens, Ralph (2012). The effects of Project Management Information Systems on decision making in a multi project envirinment [online], International Journal of Project Management 30, p. 162 - 175, Accessed on: 2012-03-26 Available at: <http://static.ow.ly/docs/CANIELS\%20 AND\%20BAKENS \%202012\%20-\%20IJPM\%2030_s0X.pdf>

[2] Cleand, D. J., King, W. R. (1983). System analysis and project management, New York: McGraw-Hill

[3] PMI Global Standard, Guide to the Project Management Body of Knowledge, (PMBOK® Guide), (2004) Third Edition, Pennsylvania, Project Management Institut, ISBN 1-930699-50-6

[4] Raymond, L., Bergeron, F. - Project management information systems: An empirical study of their impact on project managers and project success [online], (2008). International Journal of Project Management 26, p. 213-220, Accessed on: 2012-03-26 Available at: $<$ http://www.marcocoghi.com.br/site/images/Artigos/ PMIS\%20$\% 20$ Estudo $\% 20$ emp $\%$ C3\%ADrico $\% 20$ sobre $\% 20$ seu $\% 20$ impacto $\% 20$ no\% 20sucesso $\% 20$ do\%20projeto.pdf>

[5] Svozilová, Alena - Projektový manažment, (2011). Praha, Grada, ISBN 978-80-247-3611-2

[6] Swalbe, Kathy - Ǩizeni projekti̊ v IT, (2007) Brno, Computer Press, ISBN 978-80-251-1526-8

[7] Cagáňová, D., Šujanová, J, Čambál, M.: The Multiculturality Aspects in Knowledge Management within the Slovak Industrial Enterprises.In: Proceedings of the 12th European Conference on Knowledge Management - ECKM 2011 : University of Passau, Germany, 1-2 September 2011, (2011). Passau: University of Passau, ISBN 978-1-908272-10-2. - pgs. 126-127

[8] Kerzner, Harold - Project management - best practices, achieving global excellence, (2010). New Jersey, John Wiley \& Sons, ISBN 978-0-470-52829-7 